\title{
New and game-changing developments in geochemical exploration
}

\author{
Eduardo F.J. de Mulder ${ }^{1}$, Qiuming Cheng ${ }^{2}$, Frits Agterberg ${ }^{3}$, Mário Goncalves ${ }^{4}$ \\ ${ }^{1}$ Director Earth Science Matters Foundation; former President of the IUGS and Director of the International Year of Planet Earth \\ ${ }^{2}$ President of the International Association for Mathematical Geosciences \\ ${ }^{3}$ Secretary-General International Association for Mathematical Geosciences \\ ${ }^{4}$ Assistant Professor, Department of Geology, University of Lisbon
}

If you are a gold digger you want to find more gold. Therefore, you collect and analyse a maximum amount of, in particular, geological data and information as that would give you the best clues for finding new occurrences. Geological maps are the main communication tools for geologists. Such maps may be quite complex for non-geologists but even for fellow geoscientists as these often cramp a multitude of subsurface information into a 2D frame. Geochemical information ranks high on the list of most wanted information for exploration geologists. Such information normally comes from geochemical analyses of rock or soil samples. For regional inventories often geochemical data sets from stream sedimentsare used. Nation- or even continent-wide geochemical data sets have now become available for many regions on this planet.

To identify geologically relevant patterns and correlations in such maps various techniques are being used, including geostatistical ones. The current problem is that relevant geochemical anomalies such as prospective gold occurrences or heavily polluted spots may not be entirely visible on such maps as these tend to smooth or be much suppressed by normal geostatistical correlation techniques which are often performed to identify larger, regional trends. Recently, mathematical geologists developed new techniques that may spot such anomalies much better and that separate these from regional background values. These techniques proved to work so well that they should receive more attention by the geological community and in particular by geoscientists who are involved in geochemical exploration or in environmental protection.

These new techniques are based on our strongly improved understanding of geological processes and on new developments in mathematical geology. Many, if not most natural processes are quite complex and have a non-linear nature. That means that these processes do not develop linearly in time and space and that their products or results are not distributed regularly on maps or in cross sections. Their products occur in relatively narrow space and/or time intervals. Earthquakes are good examples of such non-linear processes but also cloud formation and hydrothermal mineralisation. These last processes may result in quite irregular ore bodies which nevertheless bear properties of self-similarity (the shape, or the spatial distribution, "looks" the same at different scales). The sizes of ore bodies, clouds, coastlines etc. depend on the scale at which they are measured and the outcome is not scale-independent. That was first recognized and described by Mandelbrot in 1975 when he named theseobjects as fractals or fractal geometries. Subsequent advancements have extended the concept of fractal geometry to multifractal fields such as fractal density defined on fractalgeometry. If fractals emphases on more or less self-similar geometrical properties of products of non-linear processes, multifractals were further developed for quantify complexfields or densities defined on geometries, which can be fractals. Therefore, fractals and multifractals do not obey Euclidean measuring laws and their dimensions depend on the applied measures.
The lengths of coast lines, which are the products of a wide variety of non-linear processes, depend on the lengths of the measuring rods that are used. The shorter the measuring rod, the longer the coast line is. This length is thus related to the scale by a (fractional) power. For fractal modelling Mandelbrot developed a special set of mathematical formulas.

Among the first Bölviken et al, in 1992 recognised fractal geometry theory as relevant for geochemical exploration and Cheng et al., in 1994, introduced multifractals theory and translated this into mathematical terms through a fractal model which calculates ore element Concentrations in mineral district viz their Areas. Through this (C-A) fractal model, concentration anomalies can be distinguished rather easily from their background values via a threshold point in a $\log -\log$ diagram. Several associated, refined fractal calculation models developed from the C-A method since (the Spectrum-Area, the Concentration-Distance and the Concentration-Volume fractal models). The significance of the innovation of C-A model is that it makes multifractals capable of dealing with locations rather than early global statisticalfrequency modelsthat have no locational "predictability". C-A model can be used to delineate areas based on spatial distribution of concentration with special self-similarity and fractal dimensions. This work makes fractal and multifractals theory capable of identifying or predicting locations favourable for mineral deposits.

Another major breakthrough was made in 1997, again by Cheng, who developed a method to map mineralisation as a singularity process, i.e. a non-linear process that displays for example peak results (high concentrations of minerals) in time and/or space. Local Singularity Analysis (LSA) focuses on accentuating very high or very low concentration anomalies in areas with geochemical data through their spatial relation to geological phenomena, e.g. the proximity to faults.

In Local Singularity Analysis mapping, a set of geochemical data of an area is processed twice. First, contour maps are made while applying standard geostatistical mapping and interpolation techniques (kriging, moving average, etc). Next, a local singularity mapping exercise is conducted for the same dataset. The local singularity index is estimated from the C-A fractal calculations at the samples in relation to local geological conditions (fault patterns etc.). The optimally estimated local singularity is then applied to upgrade the firstly produced maps by multiplying the contour values with a special factor. The local singularity is expressed as a power in this factor which is lessthan 2 in case of local enrichment and greaterthan 2 in places of local depletion. Comparison between LSA maps and traditionally prepared contour maps demonstrates that LSA maps display a much larger diversity in concentration values that predict occurrences of (even hidden) anomaliesmuch better. Significant progress has been made for correlation of vertical anomalies as well. In several recent papers, Zuo et al. (2015) and Chen et al. (2016) 
show convincing examples of detecting such anomalies through fractal models.

These fractal models have been tested by field evidence and proved to give reliable results for many different geological situations, both in 2D and 3D representations. Multifractal models are essentially filtering techniques and these fractal anomaly separation models, including LSA, have been integrated with geostatistical interpolation methods by Cheng in 2015 which interpolate values with variability retained. This integration improved geostatistical methods or deterministic algorithms such as inverse distance weighting for more and more accurate and convincing results.

In conclusion, geochemical exploration has been greatly facilitated by recent progress in mathematical geology, particularly by applying fractal models that separate anomalies from background concentrations. In a first stage, that was successfully done by applying such fractal models to point concentrations. Convincing attempts to translate such point data into maps were conducted in the last two decades, in particular by coupling C-A fractal anomaly separation models with geological phenomena and geostatistics without stationary assumption. The next and last challenge to properly map (even deeply seated) geochemical anomalies is to integrate fractal models and data fusion and information synthesization. As many mathematical geoscientists are working on this matter by today we may well expect a final and game-changing breakthrough soon.

\section{Bibliography}

Agterberg, F.P. (2014) Geomathematics: Theoretical Foundations, Applications and Future Developments. Quantitative Geology and Geostatistics 18.Springer, $553 \mathrm{pp}$.

Agterberg, F.P. (2012) Multifractals and geostatistics. Journal of Geochemical Exploration 122, 113-122.

Agterberg, F.P. (2013) Fractals and Spatial Statistics of Point Patterns. Journal of Earth Science 24, 1, 1-11.

Bölviken, B., Stokke, P.R., Feder, J., Jössang, T. (1992)The fractal nature of geochemical landscapes. Journal of Geochemical Exploration, 43, 91109.

Chen, G. and Cheng, Q. (2016) Singularity analysis based on wavelet transform of fractal measures for identifying geochemical anomaly in mineral exploration Computers \& Geosciences 87, 56-66.

Chen, Z., Cheng, Q., Chen, J., Xie, S. (2007) A novel iterative approach for mapping local singularities from geochemical data. Nonlinear processes in Geophysics 14, 317-324.

Cheng, Q. (2007) Mapping singularities with stream sediment geochemical data for prediction of undiscovered mineral deposits in Gejiu, Yunnan Province, China. Ore Geology Reviews32.3: 14-324.

Cheng, Q. (2006) GIS based fractal/multifractal anomaly analysis for modelling and prediction of mineralization and mineral deposits, in GIS for Geosciences', Jeff Harris and Denny Wright (eds.), Geological Association of Canada. pp. 285-296.

Cheng, Q.(2016) Fractal density and singularity analysis of heat flow over ocean ridges. Scientific Reports,doi: 10.1038/srep19167

Cheng, Q. (2015) Multifractal interpolation method for spatialdata with singularities.The Journal of The Southern African Institute of Mining and Metallurgy, 115: 235-240.

Cheng, Q., Agterberg, F.P., and Ballantyne, S.B. (1994)The separation ofgeochemical anomalies from background by fractal methods. Journal ofExploration Geochemistry, vol. 51. pp. 109-130

Cheng, Q., Agterberg, F.P., Bonham-Carter, G.F. (1996) A spatial analysis method for geochemical anomaly separation. Journal of Geochemical Exploration, 56, 183-195.

Cheng, Q. \& Agterberg F.P. (2009) Singularity analysis of ore-mineral and toxic elements in stream sediments. Computers \& Geosciences 35, 234244.

Gonçalves, M. (1998) Methods for Geochemical Anomaly Separation: The Geostatistical and Multifractal Approaches.Technical Report.FCUL. Universidade de Lisboa. $18 \mathrm{pp}$.

Turcotte, D.L. (2004)Fractals and Chaos in Geology and Geophysics.Cambridge University Press.

Liu, Y., Cheng, Q., Xia, Q., Wang, X. (2013) Application of singularity analysis for mineral potential identification using geochemical data - A case study: Nanling W-Sn-Mo polymetallicmetallogenic belt, South China. Journal of Geochemical Exploration 134: 61-72.

Wang, W., Zhao, J., Cheng, Q. (2013) Fault trace-oriented singularity mapping technique to characterize anisotropic geochemical signatures in Gejiu mineral district, China. Journal of Geochemical Exploration 134: 27-37.

Zuo, R. and Wang, J. (2015) Fractal/multifractal modeling in geochemical data: A review. Journal of Geochemical Exploration, doi: 10.1016/ j.gexplo.2014.04.010. 